\title{
Intermittent Compressive Stress Enhanced Insulin-Like Growth Factor-1 Expression in Human Periodontal Ligament Cells
}

\author{
Jittima Pumklin, ${ }^{1,2}$ Jeeranan Manokawinchoke, ${ }^{1,3}$ \\ Kanokporn Bhalang, ${ }^{4}$ and Prasit Pavasant ${ }^{1,3}$ \\ ${ }^{1}$ Research Unit of Mineralized Tissue, Faculty of Dentistry, Chulalongkorn University, Bangkok 10330, Thailand \\ ${ }^{2}$ Graduate Program in Oral Biology, Faculty of Dentistry, Chulalongkorn University, Bangkok 10330, Thailand \\ ${ }^{3}$ Department of Anatomy, Faculty of Dentistry, Chulalongkorn University, Bangkok 10330, Thailand \\ ${ }^{4}$ Department of Oral Medicine, Faculty of Dentistry, Chulalongkorn University, Bangkok 10330, Thailand
}

Correspondence should be addressed to Prasit Pavasant; prasit215@gmail.com

Received 27 February 2015; Revised 19 May 2015; Accepted 20 May 2015

Academic Editor: Rony Seger

Copyright (C) 2015 Jittima Pumklin et al. This is an open access article distributed under the Creative Commons Attribution License, which permits unrestricted use, distribution, and reproduction in any medium, provided the original work is properly cited.

\begin{abstract}
Mechanical force was shown to promote IGF-1 expression in periodontal ligament both in vitro and in vivo. Though the mechanism of this effect has not yet been proved, here we investigated the molecular mechanism of intermittent mechanical stress on IGF1 expression. In addition, the role of hypoxia on the intermittent compressive stress on IGF-1 expression was also examined. In this study, human periodontal ligament cells (HPDLs) were stimulated with intermittent mechanical stress for 24 hours. IGF-1 expression was examined by real-time polymerase chain reaction. Chemical inhibitors were used to determine molecular mechanisms of these effects. For hypoxic mimic condition, the $\mathrm{CoCl}_{2}$ supplementation was employed. The results showed that intermittent mechanical stress dramatically increased IGF-1 expression at $24 \mathrm{~h}$. The pretreatment with TGF- $\beta$ receptor I or TGF- $\beta 1$ antibody could inhibit the intermittent mechanical stress-induced IGF-1 expression. Moreover, the upregulation of TGF- $\beta 1$ proteins was detected in intermittent mechanical stress treated group. Correspondingly, the IGF-1 expression was upregulated upon being treated with recombinant human TGF- $\beta 1$. Further, the hypoxic mimic condition attenuated the intermittent mechanical stress and rhTGF- $\beta 1$-induced IGF-1 expression. In summary, this study suggests intermittent mechanical stress-induced IGF-1 expression in HPDLs through TGF- $\beta 1$ and this phenomenon could be inhibited in hypoxic mimic condition.
\end{abstract}

\section{Introduction}

In oral cavity, mechanical stress was generated in many situations, such as mastication, functional/parafunctional habits, orthodontic treatment, and occlusal trauma. Occlusal force plays a pivotal role in the regulation of periodontium homeostasis [1-3]. The mechanical force in the range of physiological condition was involved in the maintaining of the periodontium system [4]. However, the force exceeding physiological limitation could lead to pathological change, such as periodontal ligament (PDL) space widening, periodontium destruction, and alveolar bone resorption $[5,6]$.

Several lines of evidence demonstrated the effect of mechanical stress on cellular response, including periodontal ligament cells (PDLs) $[4,7]$. It has been illustrated both in vitro and in vivo that mechanical stress influenced PDL behavior. Several techniques were employed to investigate the effect of mechanical stress in vitro, for example, shear stress [8], cyclic tensile stress $[9,10]$, and static compressive stress [11]. The previous data showed that PDL responded to mechanical stress by releasing ATP $[12,13]$, increasing intracellular calcium [11, 14], changing actin filament organization [15], and upregulating of several cytokines or growth factor, including insulin-like growth factor-1 (IGF-1) [16-18].

IGFs consist of several family members such as IGF-1 and IGF-2 [19]. IGF-1 plays a role in various cellular activities, including survival, proliferation, and differentiation [20-26]. IGF-1 is involved in several kinds of cells and tissues [19] while IGF-2 plays an important role mainly during prenatal development [21]. It has been illustrated that human PDL 
expressed the IGF1 receptor, implying the ability to IGF-1 stimulation [27]. Previous report showed that IGF-1 enhanced human periodontal ligament cells (HPDLs) survival by inducing antiapoptotic molecules and downregulating proapoptotic molecules [22]. Furthermore, IGF-1 was shown to promote proliferation and osteogenic differentiation in human PDL [24]. It was noted that the application of orthodontic force on rat teeth resulted in the upregulated IGF1 release in PDL in vivo $[16,18,28]$, though the molecular mechanism, by which mechanical stress stimulates IGF-1 expression, is yet unclear.

Therefore, the present study aimed to investigate molecular signaling mechanism of intermittent mechanical stress on the IGF-1 expression in human PDLs. Furthermore, the influence of hypoxia on the intermittent mechanical stress regulated IGF-1 expression was examined.

\section{Materials and Methods}

2.1. Materials. Cell culture medium was purchased from Gibco BRL (BRL, Carlsbad, CA, USA). Culture dishes and plastic tubes were purchased from Corning (Corning, NY, USA). Cobalt chloride $\left(\mathrm{CoCl}_{2}\right)$ was purchased from Santa Cruz Biotechnology Inc. (Santa Cruz, CA, USA). Cyclohexylamine, genistein, monensin, TGF- $\beta$ receptor I inhibitor (SB431542), and recombinant human TGF- $\beta 1$ (rhTGF- $\beta 1$ ) were purchased from Sigma-Aldrich (St. Louis, MO, USA). P38 MAPK inhibitor (SB203580) was purchased from Calbiochem (Merck Chemicals, Gibbstown, NJ, USA). The TGF$\beta 1$ antibody was purchased from R\&D Systems Inc. (Minneapolis, MN, USA).

2.2. Cell Culture. All protocol was approved by the Ethics Committee of the Faculty of Dentistry, Chulalongkorn University. Third molars and premolars extracted for orthodontic reasons at the Faculty of Dentistry, Chulalongkorn University, were collected for cell isolation. The periodontal tissue was obtained from middle third of teeth's root and the tissue was cultured in standard medium (Dulbecco's modified Eagle's medium (DMEM) containing 10\% fetal bovine serum with $1 \% \mathrm{~L}$-glutamine and $1 \% \mathrm{Ab} / \mathrm{Am}$ ) and incubated at $37^{\circ} \mathrm{C}$ in a humidified atmosphere of $5 \% \mathrm{CO}_{2}$ in air. After the cells migrated from the tissue and became confluent, they were detached with $0.25 \%$ trypsin-EDTA and subcultured at a $1: 3$ ratio. In each experiment, cells from at least 3 donors were used.

2.3. Hypoxic Mimic Condition. Hypoxic mimic condition was generated by the supplementation of $\mathrm{CoCl}_{2}$. Cells were incubated with $\mathrm{CoCl}_{2}$ at 150 or $300 \mu \mathrm{M}$ for $30 \mathrm{~min}$ prior to applying intermittent mechanical stress. The control groups were cultured in the absence of $\mathrm{CoCl}_{2}$.

2.4. Intermittent Mechanical Stress Treatment. A cell compressive force loading apparatus (Thai Patent ID: 1401006767) was designed and constructed to mechanically stimulate cells in a culture plate [29]. Cells were seeded in 6-well culture plates at a density of $3 \times 10^{5}$ cells per well overnight. The cells were starved with serum-free culture medium for $4 \mathrm{~h}$ before loading force. Compressive force generator V2.5 software was used to set times, loading type, and the amount of force. In brief, the loading cycle was set to press for $1 \mathrm{~s}$ and to unpress for $2 \mathrm{~s}$ to yield a loading cycle approximately $1 / 3$ Hertz and the force amount $1.5 \mathrm{~g} / \mathrm{cm}^{2}$.

In some experiments, SB203580 $(3.5 \mu \mathrm{M}), \mathrm{CoCl}_{2}$ $(150 \mu \mathrm{M})$, cyclohexylamine $(10 \mu \mathrm{M})$, genistein $(92.5 \mu \mathrm{M})$, monensin $(100 \mu \mathrm{M}), \mathrm{SB} 431542(10 \mu \mathrm{M})$, rhTGF- $\beta 1(2 \mathrm{ng} / \mathrm{mL})$, or TGF- $\beta 1$ antibody $(5 \mu \mathrm{g} / \mathrm{mL})$ was added in the culture condition.

2.5. Cell Viability. HPDLs were seeded in 6-well plates at a density of $3 \times 10^{5}$ cells per well for applying the force and 24 well plates at density of $5 \times 10^{4}$ cells per well for being treated with $\mathrm{CoCl}_{2}$. Subsequently cells were starved with serum-free media $4 \mathrm{~h}$ before treatment. At $24 \mathrm{~h}$, HPDLs were incubated with 3-(4, 5-dimethylthiazol-2-yl)-2, 5-diphenyltetrazolium bromide solution for $30 \mathrm{~min}$. Formazan crystals were solubilized in DMSO/glycine buffer solution (0.1 M glycine/0.1 M sodium chloride $\mathrm{pH} 10$ ). The solution was further measured for an absorbance at $570 \mathrm{~nm}$ in a microplate reader (Elx800, Biotek, USA). The data were normalized to the control. All measurements were done in triplicate.

2.6. Real-Time Polymerase Chain Reaction (Real-Time PCR). After $24 \mathrm{~h}$, total cellular RNA was extracted with Trizol reagent (Molecular research Center, Cincinnati, Ohio, USA) according to the manufacturer's instructions. RNA was quantified using a NanoDrop 2000 Spectrophotometer (Thermo Scientific, Wilmington, DE, USA). One microgram of RNA sample was converted to cDNA by ImProm-II (Promega, Madison, WI, USA). Subsequently, the real-time PCR reaction was using a LightCycler instrument (Roche Diagnostics, USA) with the LightCycler 480SYBR Green I Master kit according to the manufacturer's specifications. Relative gene expression was calculated by RelQuant software (Roche Diagnostics, USA). Gene expression was normalized to the $18 \mathrm{~S}$ ribosome expression. The results are shown as fold-change values relative to the control group. The oligonucleotide sequences were as follows: IGF-1 (NM000618.3), forward $5^{\prime}$ CATGCCTGCTCAGAAGGGTA-3', reverse $5^{\prime}$-GCCTCTGATCCTTGAGGTGA-3'; $18 S$ (NR003286.2), forward $5^{\prime}$ GGCGTCCCCCAACTTCTTA-3', reverse $5^{\prime}$-GGGCATCACAGACCTGTTATT-3'.

2.7. Enzyme-Linked Immunosorbent Assay (ELISA). Radioimmunoprecipitation assay (RIPA) supplemented with protease inhibitors was used to extract cellular protein. The amount of protein was measured by a BCA protein assay kit (Pierce, Rockford, IL). Whole cell lysate and condition medium were collected at $-80^{\circ} \mathrm{C}$ for measuring the level of protein. ELISA was used for measuring the protein level according to the manuals of ELISA kits (Quantikine Immunoassay R\&D Systems). The absorbance of ELISA reaction product was measured at OD $450 \mathrm{~nm}$ using microplate reader (BioTek, ELx800, USA). 
2.8. Statistical Analyses. Data were reported as mean \pm SD. Statistical analyses were performed for two independent samples using the Student $t$-test for two-group comparisons. A one-way analysis of variance (ANOVA) followed by Turkey's post hoc analysis (SPSS, Chicago, IL, USA) was employed for three or more group comparisons. The $p$ value less than 0.05 was considered as statistically significant.

\section{Results}

3.1. Intermittent Mechanical Stress-Induced IGF-1 Expression. We began by investigating the effect of intermittent mechanical stress on HPDLs viability and morphology using a microscope at 100x magnification. HPDLs morphology was similar in all groups (see Supplementary Figure 1c in Supplementary Material available online at http://dx.doi.org/10.1155/ 2015/369874) and mechanical stress did not affect the HPDLs viability (Supplementary Figures 1a and 1b). Next, we investigated the effect of intermittent mechanical stress on IGF-1 expression in HPDLs at different time points (Figure 1). There was no significant difference in IGF-1 expression at $2 \mathrm{~h}, 4 \mathrm{~h}$, or $8 \mathrm{~h}$ between the intermittent mechanical stress-treated group and the control group. However, the IGF-1 mRNA levels were significantly increased at $24 \mathrm{~h}$ after exposing to mechanical stress. Thus, these results demonstrated intermittent mechanical stress-induced IGF-1 expression in HPDLs at $24 \mathrm{~h}$.

3.2. Intermittent Mechanical Stress Required Intermediate Protein to Induce IGF-1 Expression. We started to pretreat HPDLs with SB203580 which is p38 MAPK inhibitor prior to applying the force. Our results demonstrated that p38 MAPK inhibitor failed to block intermittent mechanical stress-induced IGF-1 expression in HPDLs (Supplementary Figure 2). Also, cycloheximide was used to inhibit protein translation (Figure 2(a)). The results showed that cycloheximide pretreatment inhibited the intermittent compressive force-induced IGF-1 mRNA expression. Further, the mechanical force-induced IGF-1 expression was also inhibited by the monensin, a protein transport inhibitor (Figure 2(b)). These results imply that the intermittent mechanical stress required the release of intermediate protein to induce IGF-1 expression. The intracellular mechanism was further identified using genistein, a tyrosine kinase inhibitor (Figure 2(c)). Corresponding to the effect of cycloheximide and monensin, genistein abolished the intermittent mechanical stress-induced transcription of IGF-1. Taken together, we concluded that intermittent mechanical stress required intermediate protein related to tyrosine kinase to induce IGF-1 expression in HPDLs.

3.3. TGF- $\beta 1$ Related to Intermittent Mechanical Stress-Induced IGF-1 Expression. As described above, the genistein inhibition blocked the intermittent mechanical stress-induced IGF1 expression. Thus, SB431542 (TGF- $\beta$ receptor type I (T $\beta$ RI) inhibitor) was chosen to clarify mechanism (Figure 3(a)). The result demonstrated that SB431542 completely suppressed intermittent mechanical stress-induced IGF-1 mRNA expression. To confirm the TGF- $\beta 1$ role in this phenomenon,

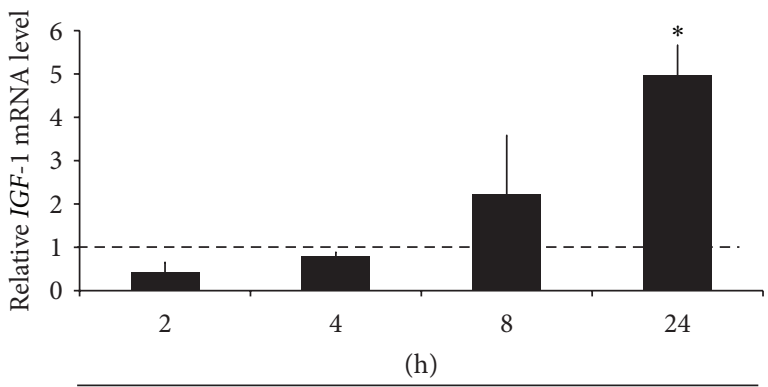

Intermittent stress (S)

FIGURE 1: Intermittent mechanical stress-induced IGF-1 expression. HPDLs were treated with intermittent mechanical stress for $2 \mathrm{~h}, 4 \mathrm{~h}$, $8 \mathrm{~h}$, and $24 \mathrm{~h}$. The IGF-1 mRNA expression was determined using real-time PCR. The dot line represented the expression levels of the control. Asterisks indicated statistically significant difference.

the neutralizing antibody against TGF- $\beta 1$ was used to block the binding of TGF- $\beta 1$ and its receptors. Correspondingly with SB431542 treatment, the neutralizing antibody against TGF- $\beta 1$ reduced the IGF-1 transcription under intermittent mechanical stress stimulation (Figure 3(b)). Finally, the addition of exogenous rhTGF- $\beta 1$ resulted in the upregulation of IGF-1 mRNA levels at $24 \mathrm{~h}$ (Figure 3(c)). However, to determine intermittent mechanical stress-induced IGF-1 expression through TGF- $\beta 1$ protein secretion, we collected the cell culture medium from intermittent mechanical stresstreated group (CMS) as well as the control group (CMC) and transferred it to another set of unstimulated HPDLs for $24 \mathrm{~h}$. Surprisingly, IGF-1 expression in those cells incubated with CMS-treated group and CMC-treated group did not differ (Figure 3(d)).

Thus, we further measured the protein levels of TGF- $\beta 1$ in both condition mediums and found that TGF- $\beta 1$ protein levels in CMS did not differ from CMC (data not shown). However, the whole cell lysate from intermittent mechanical stress-treated group expressed significantly higher TGF- $\beta 1$ protein levels than the control group (Figure 3(e)). Such evidence may imply intermittent mechanical stress-induced TGF- $\beta 1$ protein to activate IGF-1 expression in HPDLs.

\section{4. $\mathrm{CoCl}_{2}$ Inhibited the Effect of Intermittent Mechanical} Stress on IGF-1 Expression. Hypoxic condition was mimicked using the $\mathrm{CoCl}_{2}$ supplementation at $150-300 \mu \mathrm{M}$. The results showed that $\mathrm{CoCl}_{2}$ did not significantly affect $I G F-1$ expression in normal culture (Figure 4(a)). However, $\mathrm{CoCl}_{2}$ significantly inhibited IGF-1 expression upon the intermittent stress treatment in a $\mathrm{CoCl}_{2}$ dose-dependent manner (Figure 4(a)). Further, $\mathrm{CoCl}_{2}$ also inhibited the rhTGF- $\beta 1$-induced IGF1 expression (Figure 4(b)). Therefore, we hypothesized that $\mathrm{CoCl}_{2}$ affect the intracellular signaling of TGF- $\beta 1$ in order to induce $I G F-1$ expression in HPDLs.

\section{Discussion}

The physiological force is one of the important factors in maintaining periodontium homeostasis [4]. However, in 


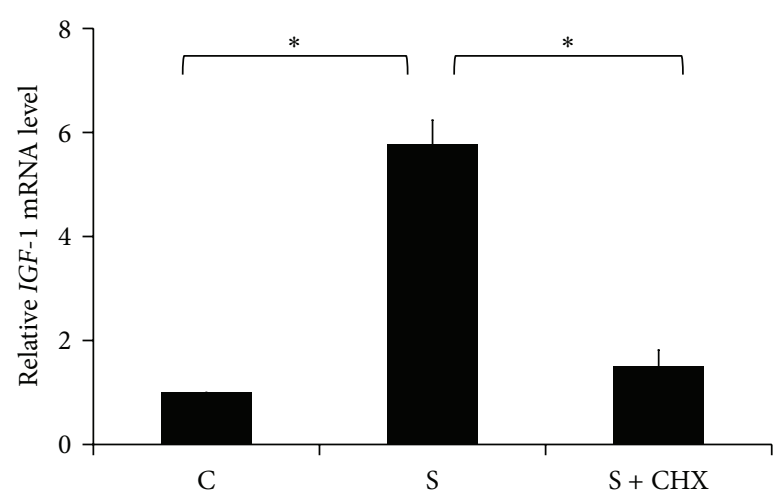

(a)

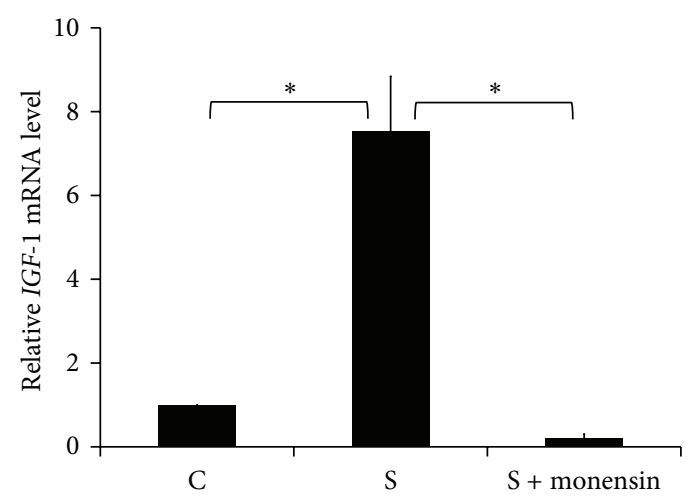

(b)

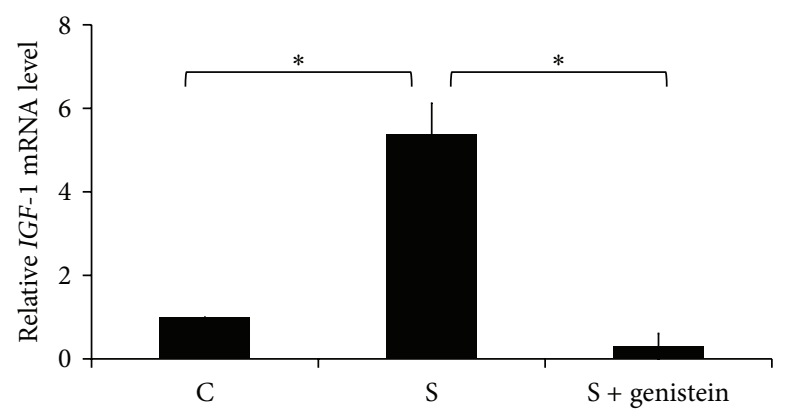

(c)

FIGURE 2: Intermittent mechanical stress required the intermediate protein to induce IGF-1 expression. (a) Cycloheximide (CHX; $10 \mu \mathrm{M})$, (b) genistein $(92.5 \mu \mathrm{M})$, and (c) monensin $(100 \mu \mathrm{M})$ were pretreated 30 min prior to applying the intermittent mechanical stress for $24 \mathrm{~h}$. IGF-1 mRNA expression was determined by real-time PCR. Asterisks indicated statistically significant difference. C: the control condition; S: the intermittent mechanical stress treatment condition.

pathological condition (i.e., periodontal disease), the physiological force may lead to tissue destruction [30,31]. Thus, this study demonstrated the influence of intermittent mechanical stress on IGF-1 expression. IGF-1 is an important growth factor regulating cell proliferation and differentiation in HPDLs $[23,24]$. We found that the intermittent mechanical stress promoted IGF-1 expression via TGF- $\beta 1$ signaling pathway. Further, the hypoxic mimic condition using $\mathrm{CoCl}_{2}$ could attenuate the intermittent compressive stress-induced IGF-1 expression, implying that occlusal force may not induce IGF-1 expression in deep periodontal pocket, where it was considered as hypoxic microenvironment. The suggested model of intermittent mechanical stress-induced IGF-1 expression in HPDLs is demonstrated in Figure 4(c).

IGF-1 plays an important role in bone growth and development $[32,33]$ and promotes cell proliferation and osteogenic differentiation in HPDLs [20, 24]. In addition, the in vitro study demonstrated that IGF-1 is a growth factor that responds early to mechanical stress [17]. In the in vivo orthodontic tooth movement model, the orthodontic force or occlusal stimuli significantly enhanced IGF-1 expression in HPDLs [16]. Correspondingly, our data showed intermittent mechanical stress-induced IGF-1 expression in HPDLs. However, no evidence explores the detail signaling mechanism of this action. Thus, the present study was the first report which demonstrated that the intermittent mechanical stress promoted IGF-1 expression by HPDLs through TGF- $\beta 1$ pathway.
The present study showed that the intermittent compressive stress enhanced the increase of TGF- $\beta 1$ protein expression in cell lysate and the addition of rhTGF- $\beta 1$ resulted in the upregulation of IGF-1 expression similar to those treated with the intermittent mechanical stress. Correspondingly, it was previously demonstrated that the TGF- $\beta 1$ treatment significantly increased IGF-1 expression in dose- and timedependent manner in human marrow stromal osteoblast precursor cells [34]. It was also shown that single-dose administration of TGF- $\beta 1$ promoted the osteogenic maker expression via the expression of IGF-1 since the knockdown of insulin receptor substrate 1 could attenuate the TGF- $\beta 1$-induced osteogenic marker expression [35]. However, it should be noted that the repeat-dose of TGF- $\beta 1$ led to the inhibition of IGF-1 expression and subsequently caused the suppression of osteogenic differentiation in HPDLs, human mesenchymal stem cells, and murine preosteoblast (MC3T3-E1 cells) [35]. Moreover, TGF- $\beta$ inhibited migration in $\mathrm{C} 2 \mathrm{Cl} 2$ skeletal muscle satellite cell and P19 embryonal carcinoma cell via decreasing IGF-1 [36]. Collectively, several lines of evidence indicated the close relationship between TGF- $\beta 1$ and IGF-1 in a positive or negative regulator depending on cell types.

The influence of hypoxia can be found in inflamed tissue including periodontitis. The hypoxic condition is associated with imbalance between elevating the oxygen demand from inflammatory cells penetration and inadequate oxygen supply by poor perfusion [26, 37, 38]. In periodontitis, 


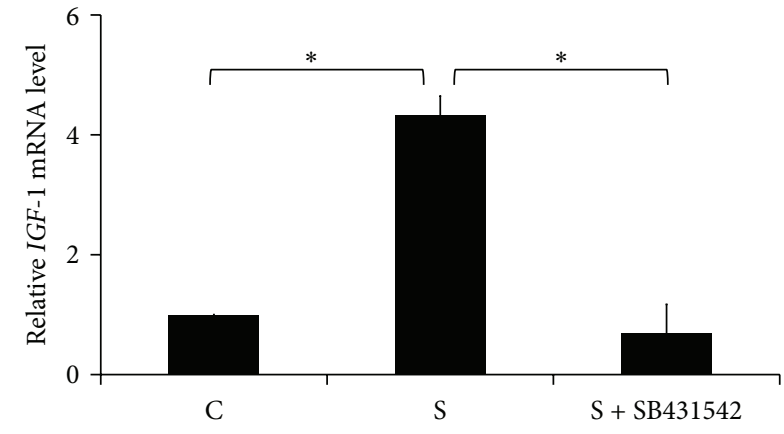

(a)

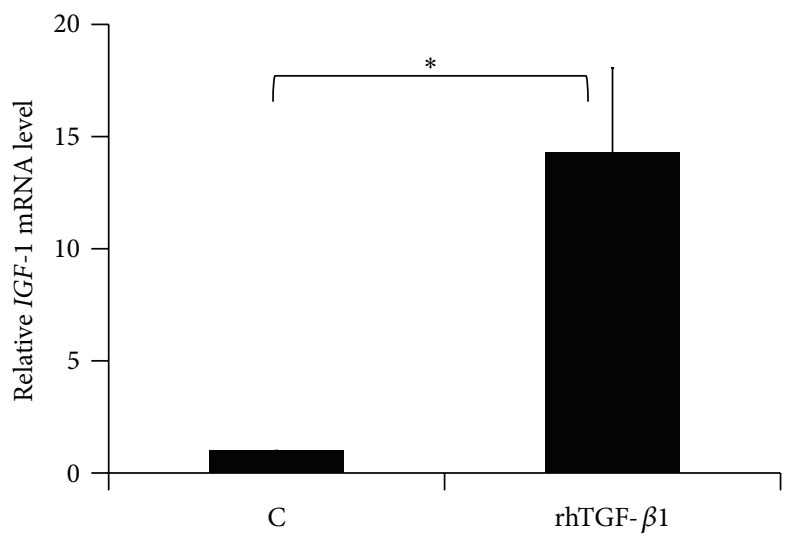

(c)

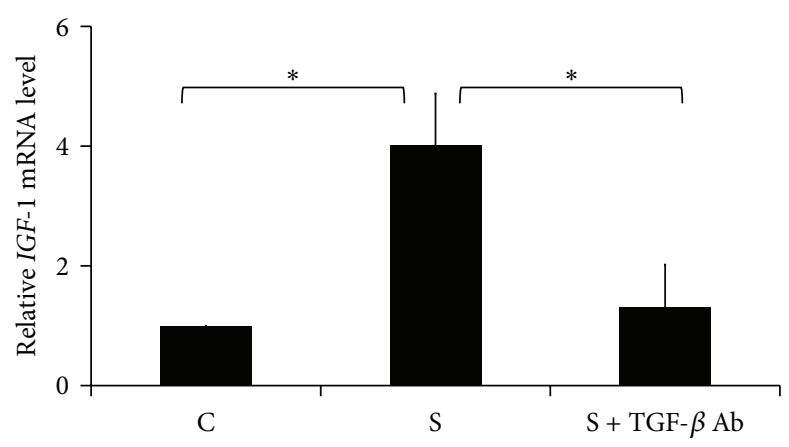

(b)

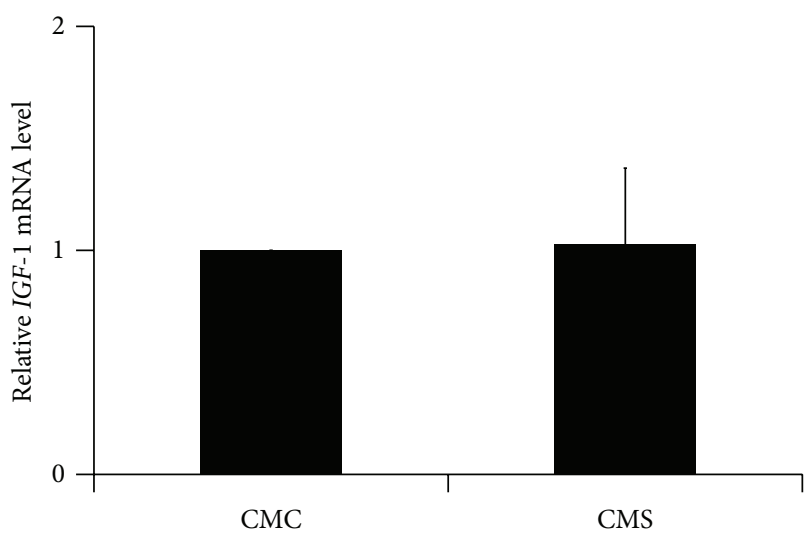

(d)

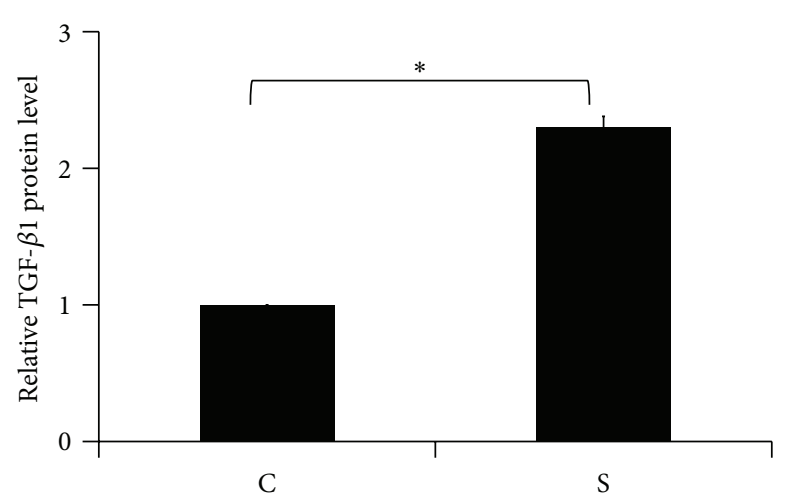

(e)

Figure 3: TGF- $\beta 1$ related to intermittent mechanical stress-induced IGF-1 expression. (a) SB431542 (10 $\mu$ M) or (b) TGF- $\beta 1$ neutralizing antibody $(\mathrm{Ab})(5 \mu \mathrm{g} / \mathrm{mL})$ was used to pretreat HPDLs $30 \mathrm{~min}$ before applying the intermittent mechanical stress for $24 \mathrm{~h}$. The IGF-1 expression was measured by real-time PCR. (c) IGF-1 mRNA levels were examined after HPDLs were treated with rhTGF- $\beta 1$ ( $2 \mathrm{ng} / \mathrm{mL})$ for $24 \mathrm{~h}$. (d) HPDLs were treated with cell culture medium from intermittent mechanical stress-treated group (CMS) or untreated group (CMC) $24 \mathrm{~h}$. The IGF-1 mRNA levels were determined by real-time PCR. (e) The TGF- $\beta 1$ protein in whole cell lysate was measured by ELISA assay. Asterisks indicated statistically significant difference. C: the control condition; S: the intermittent mechanical stress treatment condition.

the HPDLs respond to hypoxia by increasing the inflammatory mediator $[39,40]$ and enhancement of alveolar bone loss $[41,42]$. Therefore, both intermittent mechanical stress and hypoxia are contributing factors to periodontal disease progression, leading us to investigate the effect of combining those two factors on HPDLs. In this study, artificial hypoxic agent, $\mathrm{CoCl}_{2}$, abolished the intermittent mechanical stressinduced IGF-1 expression in HPDLs. This condition represents the clinical situation, where the physiological force was loaded on periodontitis' teeth. Therefore, this data assumed that hypoxia attenuated the intermittent mechanical stressinduced osteogenic differentiation through decrease in $I G F$ 1 expression in HPDLs. However, the further investigation is indeed required to claim this hypothesis. Recently, it was demonstrated that the cyclic tensile stress under hypoxic condition regulated proliferation and osteogenic differentiation in HPDLs via MAPK pathway [9]. Thus, this information could imply that the type, amount, and direction of force may 


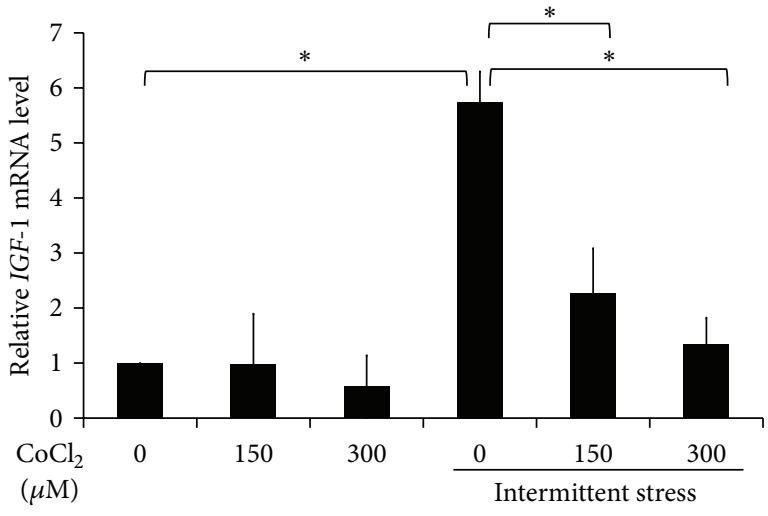

(a)

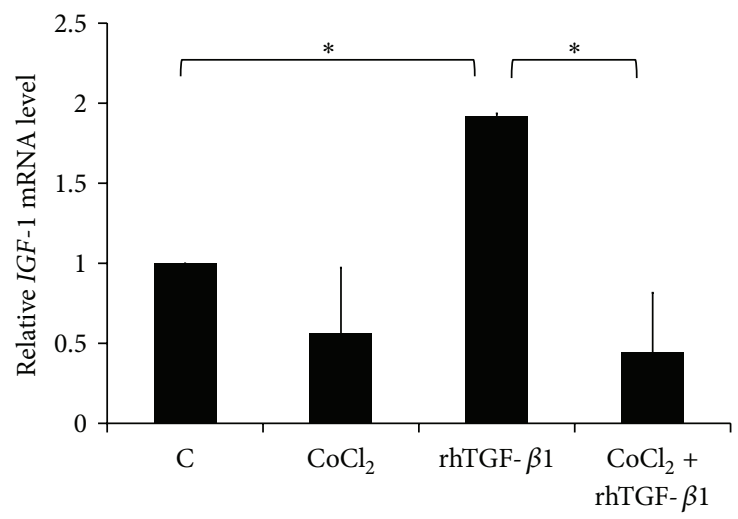

(b)

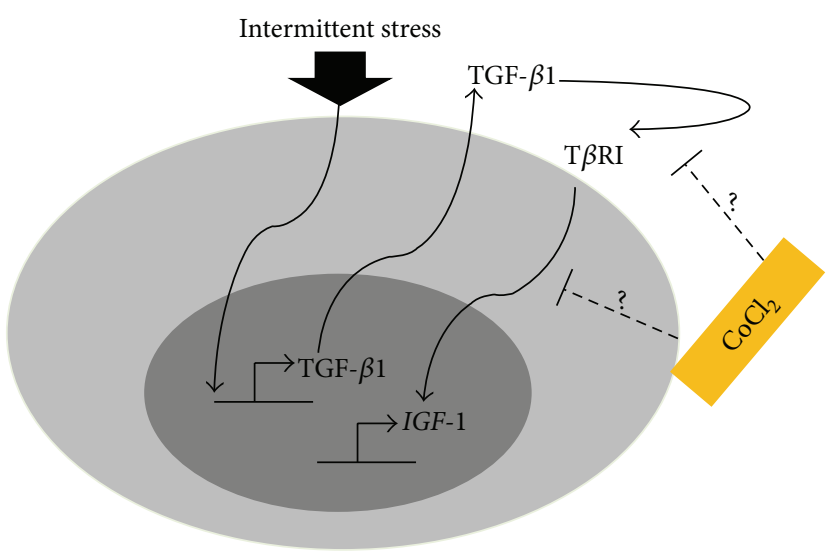

(c)

FIGURE 4: $\mathrm{CoCl}_{2}$ inhibited the effect of intermittent mechanical stress on IGF-1 expression. (a) HPDLs were treated with CoCl $\mathrm{Cl}_{2}(150$ and $300 \mu \mathrm{M})$ in the presence or absence of intermittent mechanical stress stimulation for $24 \mathrm{~h}$. The IGF- 1 expression was evaluated by real-time PCR. (b) IGF-1 expression was examined after HPDLs were treated with rhTGF- $\beta 1\left(2 \mathrm{ng} / \mathrm{mL}\right.$ ) with and without the CoCl $\mathrm{l}_{2}(150 \mu \mathrm{M})$ for $24 \mathrm{~h}$. (c) The illustration represented the proposed signaling mechanism of the intermittent mechanical stress-induced IGF-1 expression by HPDLs. Asterisks indicated statistically significant difference. C: the control condition; S: the intermittent mechanical stress treatment condition.

play an important role in the HPDLs' response under hypoxic condition.

$\mathrm{CoCl}_{2}$, an inducer of hypoxia, is well known and commonly employed to establish the physical hypoxic-like condition in cell culture [43-46]. Some studies demonstrated the similar effect of $\mathrm{CoCl}_{2}$ and physical hypoxia [47-49]. Our previous study reported that $\mathrm{CoCl}_{2}$ could stabilize hypoxiainducible factor-1 alpha (HIF- $1 \alpha$ ), a key transcription factor for hypoxic condition in HPDLs [50]. In contrast to some lines of evidence, there were some aspects of detailed different mechanisms between hypoxia and $\mathrm{CoCl}_{2}[51,52]$. Thus, the results from the present study may not be directly implied to those of physical hypoxia setting. Further experiment is required to fully investigate the role of hypoxia on the intermittent compressive stress-induced IGF-1 expression in HPDLs.

The present study showed that hypoxic mimic condition attenuated the intermittent mechanical stress-induced IGF1 expression in HPDLs. However, in unloading condition, $\mathrm{CoCl}_{2}$ did not significantly affect IGF-1 expression. Corresponding to previous studies, physical hypoxia and $\mathrm{CoCl}_{2}$ attenuated IGF-1 expression via the suppression of Runx2 and the induction of C/EBP $\delta$ in rat osteoblasts [53]. Runx2 could bind to the upstream element in IGF-1 gene promoter and regulated IGF-1 expression [53]. Further, in systemic investigation, the serum IGF levels were decreased in acute respiratory distress patients, which were a hypoxia state [54]. On the contrary, it was shown that $\mathrm{CoCl}_{2}$ decreased IGF-1 expression in fish muscle [55]. In addition, the IGF-1 expression was upregulated by hypoxia in HepG2 cells [56]. Further, in the present study, we demonstrated that $\mathrm{CoCl}_{2}$ inhibited rhTGF- $\beta 1$-induced IGF-1 expression in HPDLs. The previous study demonstrated that hypoxia inhibited TGF- $\beta 1-$ induced transformation in rabbit corneal keratocyte [57]. Taken together, further study to evaluate the mechanism of hypoxic mimic condition on the inhibition of TGF- $\beta 1$-induced IGF-1 expression in HPDLs is necessitated.

In conclusion, our results indicated the intermittent mechanical stress-induced IGF-1 expression via TGF- $\beta 1$ signaling pathway in HPDLs. Further, the hypoxic mimic agent could abolish this effect. Our data showed the important intermittent mechanical stress to regulate HPDLs activity. 


\section{Conflict of Interests}

The authors declare that there is no conflict of interests regarding the publication of this paper.

\section{Acknowledgments}

The authors thank Assistant Professor Dr. Thanaphum Osathanon for critical reading and suggestion on this paper. This study was supported by an Integrated Innovation Academic Center (IIAC), Chulalongkorn University Centenary Academic Development Project, the Research Chair Grant 2012, and the National Science and Technology Development Agency (NSTDA).

\section{References}

[1] H. Kitaura, K. Kimura, M. Ishida et al., "Effect of cytokines on osteoclast formation and bone resorption during mechanical force loading of the periodontal membrane," The Scientific World Journal, vol. 2014, Article ID 617032, 7 pages, 2014.

[2] A. D. Berendsen, T. H. Smit, X. F. Walboomers, V. Everts, J. A. Jansen, and A. L. J. J. Bronckers, "Three-dimensional loading model for periodontal ligament regeneration in vitro," Tissue Engineering Part C: Methods, vol. 15, no. 4, pp. 561-570, 2009.

[3] N. Hacopian, T. H. Nik, M. H. Ghahremani, H. R. Rahimi, and S. N. Ostad, "Effects of continuous and interrupted forces on gene transcription in periodontal ligament cells in vitro," Acta Medica Iranica, vol. 49, no. 10, pp. 643-649, 2011.

[4] C. A. G. McCulloch, P. Lekic, and M. D. McKee, "Role of physical forces in regulating the form and function of the periodontal ligament," Periodontology 2000, vol. 24, no. 1, pp. 56-72, 2000.

[5] M. Kaku, K. Uoshima, Y. Yamashita, and H. Miura, "Investigation of periodontal ligament reaction upon excessive occlusal load-osteopontin induction among periodontal ligament cells," Journal of Periodontal Research, vol. 40, no. 1, pp. 59-66, 2005.

[6] K. Nozaki, M. Kaku, Y. Yamashita, M. Yamauchi, and H. Miura, "Effect of cyclic mechanical loading on osteoclast recruitment in periodontal tissue," Journal of Periodontal Research, vol. 45, no. 1, pp. 8-15, 2010.

[7] D. Pavlin and J. Gluhak-Heinrich, "Effect of mechanical loading on periodontal cells," Critical Reviews in Oral Biology and Medicine, vol. 12, no. 5, pp. 414-424, 2001.

[8] M. S. Lee, M.-T. Sun, S.-T. Pang et al., "Evaluation of differentially expressed genes by shear stress in human osteoarthritic chondrocytes in vitro," Chang Gung Medical Journal, vol. 32, no. 1, pp. 42-50, 2009.

[9] L. Li, M.-X. Han, S. Li, Y. Xu, and L. Wang, "Hypoxia regulates the proliferation and osteogenic differentiation of human periodontal ligament cells under cyclic tensile stress via mitogenactivated protein kinase pathways," Journal of Periodontology, vol. 85, no. 3, pp. 498-508, 2014.

[10] B.-W. Wang, G.-J. Wu, W.-P. Cheng, and K.-G. Shyu, "Mechanical stretch via transforming growth factor- $\beta 1$ activates microRNA-208a to regulate hypertrophy in cultured rat cardiac myocytes," Journal of the Formosan Medical Association, vol. 112, no. 10, pp. 635-643, 2013.
[11] K. Kanjanamekanant, P. Luckprom, and P. Pavasant, "Mechanical stress-induced interleukin-1beta expression through adenosine triphosphate/P2X7 receptor activation in human periodontal ligament cells," Journal of Periodontal Research, vol. 48, no. 2, pp. 169-176, 2013.

[12] P. Luckprom, S. Wongkhantee, T. Yongchaitrakul, and P. Pavasant, "Adenosine triphosphate stimulates RANKL expression through P2Y1 receptor-cyclo-oxygenase-dependent pathway in human periodontal ligament cells," Journal of Periodontal Research, vol. 45, no. 3, pp. 404-411, 2010.

[13] S. Wongkhantee, T. Yongchaitrakul, and P. Pavasant, "Mechanical stress induces osteopontin via ATP/P2Y1 in periodontal cells," Journal of Dental Research, vol. 87, no. 6, pp. 564-568, 2008.

[14] R. M. S. De Araujo, Y. Oba, and K. Moriyama, "Identification of genes related to mechanical stress in human periodontal ligament cells using microarray analysis," Journal of Periodontal Research, vol. 42, no. 1, pp. 15-22, 2007.

[15] R. M. S. de Araujo, Y. Oba, S. Kuroda, E. Tanaka, and K. Moriyama, "RhoE regulates actin cytoskeleton organization in human periodontal ligament cells under mechanical stress," Archives of Oral Biology, vol. 59, no. 2, pp. 187-192, 2014.

[16] Y. Kheralla, W. Götz, A. Kawarizadeh, B. Rath-Deschner, and A. Jäger, "IGF-I, IGF-IR and IRS1 expression as an early reaction of PDL cells to experimental tooth movement in the rat," Archives of Oral Biology, vol. 55, no. 3, pp. 215-222, 2010.

[17] B. Rath-Deschner, J. Deschner, S. Reimann, A. Jager, and W. Gotz, "Regulatory effects of biomechanical strain on the insulin-like growth factor system in human periodontal cells," Journal of Biomechanics, vol. 42, no. 15, pp. 2584-2589, 2009.

[18] S. Termsuknirandorn, J. Hosomichi, and K. Soma, "Occlusal stimuli influence on the expression of IGF-1 and the IGF-1 receptor in the rat periodontal ligament," Angle Orthodontist, vol. 78, no. 4, pp. 610-616, 2008.

[19] S. Raja, G. Byakod, and P. Pudakalkatti, "Growth factors in periodontal regeneration," International Journal of Dental Hygiene, vol. 7, no. 2, pp. 82-89, 2009.

[20] F. A. M. de Abreu, C. L. Ferreira, G. A. B. Silva et al., "Effect of PDGF-BB, IGF-I growth factors and their combination carried by liposomes in tooth socket healing," Brazilian Dental Journal, vol. 24, no. 4, pp. 299-307, 2013.

[21] W. Götz, D. Kunert, D. Zhang, A. Kawarizadeh, S. Lossdörfer, and A. Jäger, "Insulin-like growth factor system components in the periodontium during tooth root resorption and early repair processes in the rat," European Journal of Oral Sciences, vol. 114, no. 4, pp. 318-327, 2006.

[22] X. Han and S. Amar, "IGF-1 signaling enhances cell survival in periodontal ligament fibroblasts vs. gingival fibroblasts," Journal of Dental Research, vol. 82, no. 6, pp. 454-459, 2003.

[23] A. C. P. Sant’Ana, M. M. Marques, E. C. Barroso, E. Passanezi, and M. L. R. de Rezende, "Effects of TGF-betal, PDGF-BB, and IGF-1 on the rate of proliferation and adhesion of a periodontal ligament cell lineage in vitro," Journal of Periodontology, vol. 78, no. 10, pp. 2007-2017, 2007.

[24] Y. Yu, J. Mu, Z. Fan et al., "Insulin-like growth factor 1 enhances the proliferation and osteogenic differentiation of human periodontal ligament stem cells via ERK and JNK MAPK pathways," Histochemistry and Cell Biology, vol. 137, no. 4, pp. 513-525, 2012.

[25] J. Li, Z. Yang, Z. Li, L. Gu, Y. Wang, and C. Sung, "Exogenous IGF-1 promotes hair growth by stimulating cell proliferation and down regulating TGF-betal in C57BL/6 mice in vivo," 
Growth Hormone and IGF Research, vol. 24, no. 2-3, pp. 89-94, 2014.

[26] R. S. Pais, N. Moreno-Barriuso, I. Hernández-Porras, I. P. López, J. De Las Rivas, and J. G. Pichel, "Transcriptome analysis in prenatal IGF1-deficient mice identifies molecular pathways and target genes involved in distal lung differentiation," PLOS ONE, vol. 8, no. 12, Article ID e83028, 2013.

[27] W. Götz, M. Heinen, S. Lossdörfer, and A. Jäger, "Immunohistochemical localization of components of the insulin-like growth factor system in human permanent teeth," Archives of Oral Biology, vol. 51, no. 5, pp. 387-395, 2006.

[28] P. Proff, C. Reicheneder, A. Faltermeier, D. Kubein-Meesenburg, and P. Römer, "Effects of mechanical and bacterial stressors on cytokine and growth-factor expression in periodontal ligament cells," Journal of Orofacial Orthopedics, vol. 75, no. 3, pp. 191-202, 2014.

[29] J. Manokawinchoke, N. Limjeerajarus, C. Limjeerajarus, P. Sastravaha, V. Everts, and P. Pavasant, "Mechanical forceinduced TGFB1 increases expression of SOST/POSTN by hPDL cells," Journal of Dental Research, 2015.

[30] J.-Y. Joo, E.-Y. Kwon, and J.-Y. Lee, "Intentional passive eruption combined with scaling and root planing of teeth with moderate chronic periodontitis and traumatic occlusion," Journal of Periodontal and Implant Science, vol. 44, no. 1, pp. 20-24, 2014.

[31] S. Nakatsu, Y. Yoshinaga, A. Kuramoto et al., "Occlusal trauma accelerates attachment loss at the onset of experimental periodontitis in rats," Journal of Periodontal Research, vol. 49, no. 3 , pp. 314-322, 2014.

[32] V. Locatelli and V. E. Bianchi, "Effect of GH/IGF-1 on Bone Metabolism and Osteoporsosis," International Journal of Endocrinology, vol. 2014, Article ID 235060, 25 pages, 2014.

[33] K.-H. Lau, D. J. Baylink, X.-D. Zhou et al., "Osteocyte-derived insulin-like growth factor I is essential for determining bone mechanosensitivity," The American Journal of PhysiologyEndocrinology and Metabolism, vol. 305, no. 2, pp. E271-E281, 2013.

[34] M. Kveiborg, A. Flyvbjerg, E. F. Eriksen, and M. Kassem, "Transforming growth factor- $\beta 1$ stimulates the production of insulin-like growth factor-I and insulin-like growth factorbinding protein-3 in human bone marrow stromal osteoblast progenitors," Journal of Endocrinology, vol. 169, no. 3, pp. 549$561,2001$.

[35] H. Ochiai, S. Okada, A. Saito et al., "Inhibition of insulinlike growth factor-1 (IGF-1) expression by prolonged transforming growth factor- $\beta 1$ (TGF- $\beta 1$ ) administration suppresses osteoblast differentiation," Journal of Biological Chemistry, vol. 287, no. 27, pp. 22654-22661, 2012.

[36] E. J. Schabort, M. van der Merwe, and C. U. Niesler, “TGF- $\beta$ isoforms inhibit IGF-1-induced migration and regulate terminal differentiation in a cell-specific manner," Journal of Muscle Research and Cell Motility, vol. 31, no. 5-6, pp. 359-367, 2011.

[37] J. Karhausen, V. H. Haase, and S. P. Colgan, "Inflammatory hypoxia: role of hypoxia-inducible factor," Cell Cycle, vol. 4, no. 2, pp. 256-258, 2005.

[38] H. K. Eltzschig and P. Carmeliet, "Hypoxia and inflammation," The New England Journal of Medicine, vol. 364, no. 7, pp. 656665, 2011.

[39] L. Gölz, S. Memmert, B. Rath-Deschner et al., "LPS from $P$. gingivalis and hypoxia increases oxidative stress in periodontal ligament fibroblasts and contributes to periodontitis," Mediators of Inflammation, vol. 2014, Article ID 986264, 13 pages, 2014.
[40] C. Jian, C. Li, Y. Ren et al., "Hypoxia augments lipopolysaccharide-induced cytokine expression in periodontal ligament cells," Inflammation, vol. 37, no. 5, pp. 1413-1423, 2014.

[41] H. Motohira, J. Hayashi, J. Tatsumi, M. Tajima, H. Sakagami, and K. Shin, "Hypoxia and reoxygenation augment boneresorbing factor production from human periodontal ligament cells," Journal of Periodontology, vol. 78, no. 9, pp. 1803-1809, 2007.

[42] A. R. Terrizzi, J. Fernandez-Solari, C. M. Lee et al., "Alveolar bone loss associated to periodontal disease in lead intoxicated rats under environmental hypoxia," Archives of Oral Biology, vol. 58, no. 10, pp. 1407-1414, 2013.

[43] A. Kumar, L. Rani, B. Dhole, and P. K. Chaturvedi, "Oxygen as a regulator of MA-10 cell functions: effect of cobalt chloride on vascular endothelial growth factor production," Andrologia, vol. 44, no. 1, pp. 615-620, 2012.

[44] A. Kumar, L. Rani, and B. Dhole, "Role of oxygen in the regulation of Leydig tumor derived MA-10 cell steroid production: the effect of cobalt chloride," Systems Biology in Reproductive Medicine, vol. 60, no. 2, pp. 112-118, 2014.

[45] K. Lin, P. Ye, J. Liu, F. He, and W. Xu, "Endostar inhibits hypoxiainduced cell proliferation and migration via the hypoxiainducible factor- $1 \alpha /$ vascular endothelial growth factor pathway in vitro," Molecular Medicine Reports, 2014.

[46] S. Ambrosini, E. Sarchielli, P. Comeglio et al., "Fibroblast growth factor and endothelin-1 receptors mediate the response of human striatal precursor cells to hypoxia," Neuroscience, vol. 289, pp. 123-133, 2015.

[47] K. S. Kim, V. Rajagopal, C. Gonsalves, C. Johnson, and V. K. Kalra, "A novel role of hypoxia-inducible factor in cobalt chloride- and hypoxia-mediated expression of IL- 8 chemokine in human endothelial cells," Journal of Immunology, vol. 177, no. 10, pp. 7211-7224, 2006.

[48] S.-H. Hsu, C.-T. Chen, and Y.-H. Wei, "Inhibitory effects of hypoxia on metabolic switch and osteogenic differentiation of human mesenchymal stem cells," Stem Cells, vol. 31, no. 12, pp. 2779-2788, 2013.

[49] Shweta, K. P. Mishra, S. Chanda, S. B. Singh, and L. Ganju, "A comparative immunological analysis of $\mathrm{CoCl}_{2}$ treated cells with in vitro hypoxic exposure," Biometals, vol. 28, no. 1, pp. 175-185, 2015.

[50] T. Osathanon, P. Vivatbutsiri, W. Sukarawan, W. Sriarj, P. Pavasant, and S. Sooampon, "Cobalt chloride supplementation induces stem-cell marker expression and inhibits osteoblastic differentiation in human periodontal ligament cells," Archives of Oral Biology, vol. 60, no. 1, pp. 29-36, 2015.

[51] H.-H. Kim, S. E. Lee, W. J. Chung et al., "Stabilization of hypoxia-inducible factor- $1 \alpha$ is involved in the hypoxic stimuliinduced expression of vascular endothelial growth factor in osteoblastic cells," Cytokine, vol. 17, no. 1, pp. 14-27, 2002.

[52] P. Gupta, S. Nath, R. Meena, and N. Kumar, "Comparative effects of hypoxia and hypoxia mimetic cobalt chloride on in vitro adhesion, biofilm formation and susceptibility to amphotericin B of Candida glabrata," Journal de Mycologie Médicale, vol. 24, no. 4, pp. e169-e177, 2014.

[53] T. L. McCarthy, Z. Yun, J. A. Madri, and M. Centrella, "Stratified control of IGF-I expression by hypoxia and stress hormones in osteoblasts," Gene, vol. 539, no. 1, pp. 141-151, 2014.

[54] R. J. Custodio, V. I. do Carmo Custodio, C. A. Scrideli et al., "Impact of hypoxia on IGF-I, IGF-II, IGFBP-3, ALS and IGFBP1 regulation and on IGF1R gene expression in children," Growth Hormone and IGF Research, vol. 22, no. 5, pp. 186-191, 2012. 
[55] D. Ekinci, S. B. Ceyhun, E. Aksakal, and O. Erdoǧan, "IGF and GH mRNA levels are suppressed upon exposure to micromolar concentrations of cobalt and zinc in rainbow trout white muscle," Comparative Biochemistry and Physiology C Toxicology and Pharmacology, vol. 153, no. 3, pp. 336-341, 2011.

[56] Y.-H. Joung, M.-Y. Lee, E.-J. Lim et al., "Hypoxia activates the IGF-1 expression through STAT5b in human HepG2 cells," Biochemical and Biophysical Research Communications, vol. 358, no. 3, pp. 733-738, 2007.

[57] D. Xing and J. A. Bonanno, "Hypoxia reduces TGFbetalinduced corneal keratocyte myofibroblast transformation," Molecular Vision, vol. 15, pp. 1827-1834, 2009. 

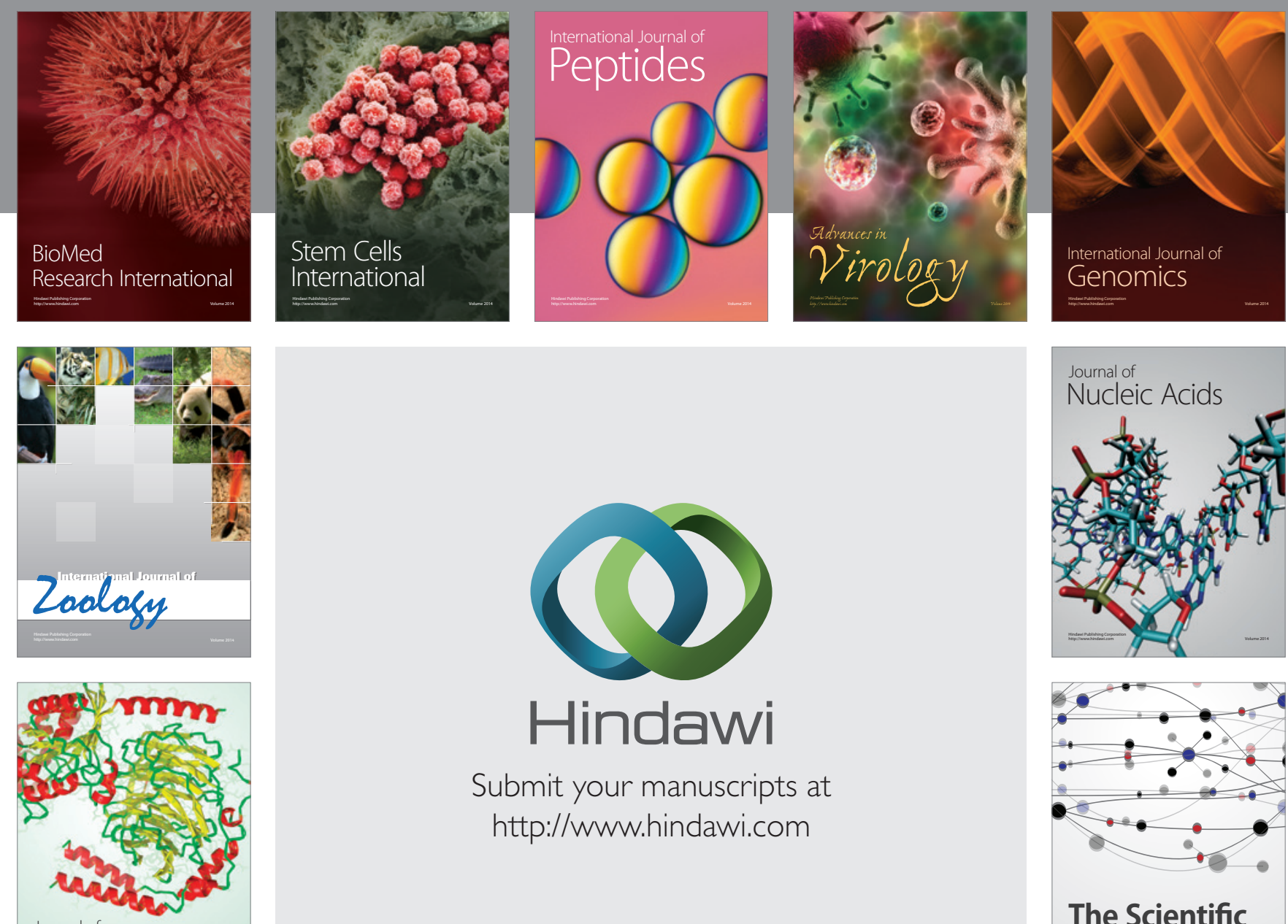

Submit your manuscripts at

http://www.hindawi.com

Journal of
Signal Transduction
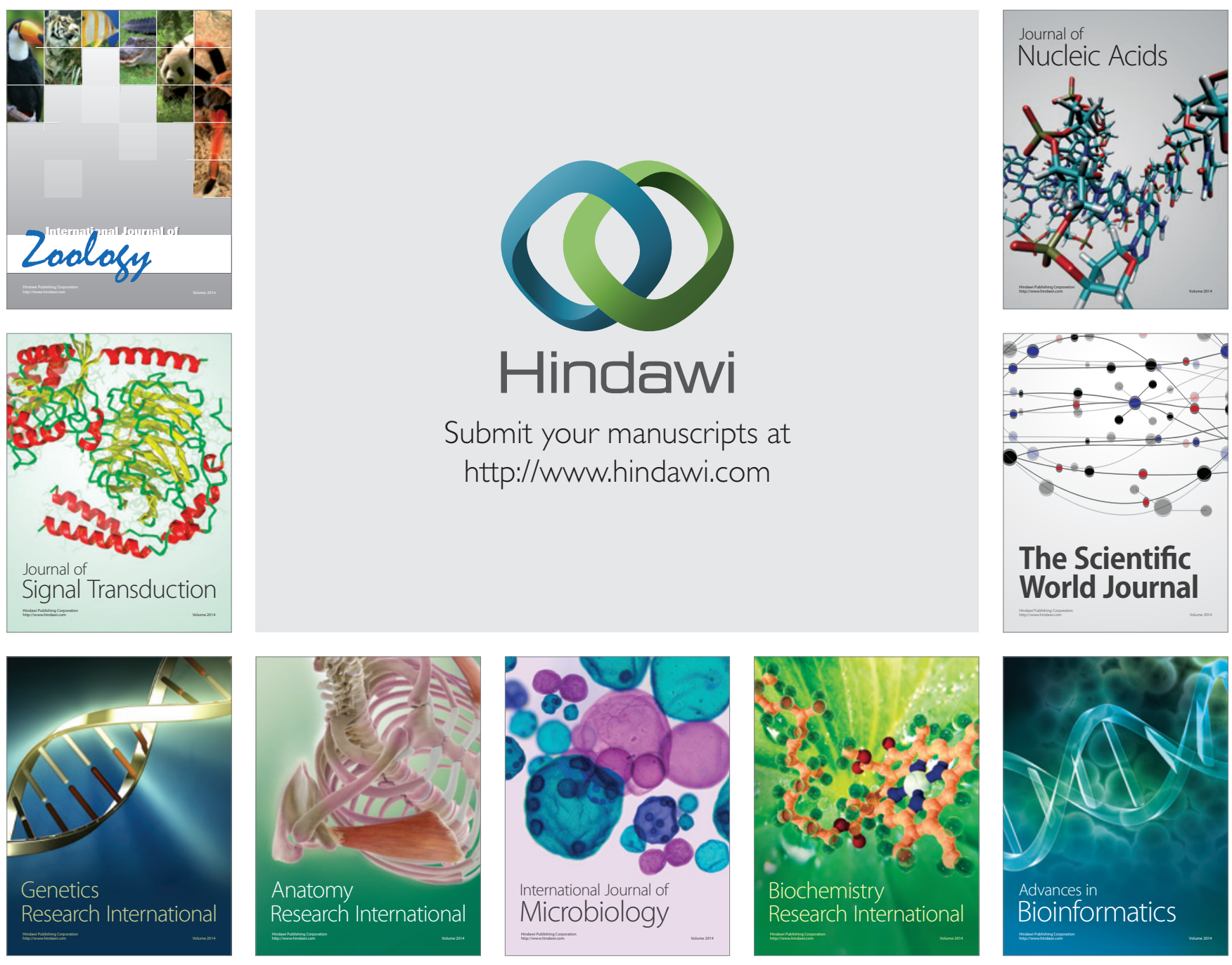

The Scientific World Journal
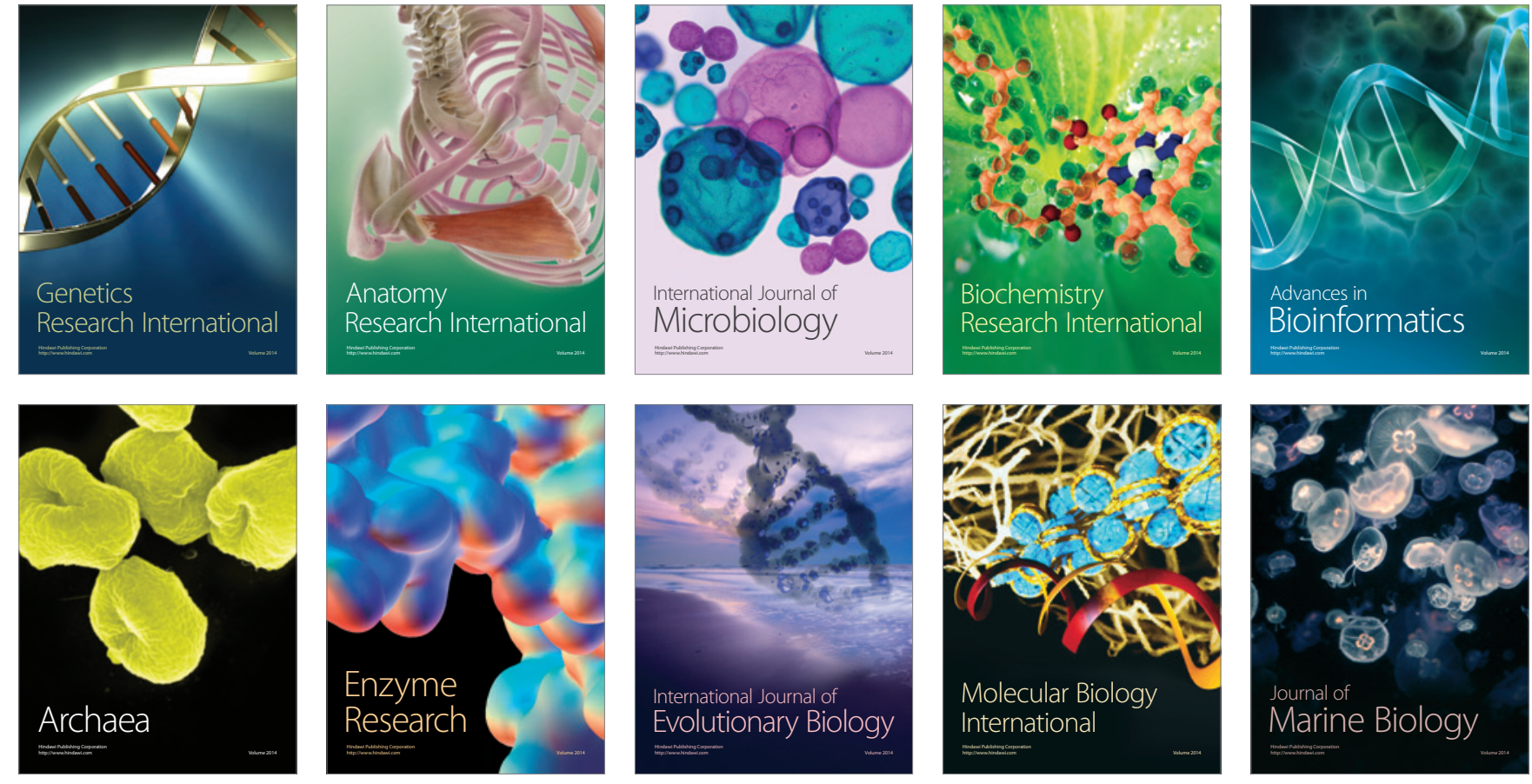